\title{
Study on Infertility-Etiology, Medication Therapy Management, and Outcomes at a Tertiary Care Hospital
}

\author{
${ }^{1}$ Purvi K Khanuja, ${ }^{2}$ Juby A Sunny, ${ }^{3}$ Sunita B Pawar, ${ }^{4}$ Vandana Nimbargi
}

\section{ABSTRACT}

Aim: The aim of the article is to study infertility —etiology, medication therapy management, and outcomes in a tertiary care hospital.

Objectives: The purpose of this study was to compare the outcomes of standard aetiology wise treatment protocols of infertility and the various causes which may be a contributing factor to infertility.

Materials and methods: A prospective observational study was conducted for 6 months at a tertiary care hospital. Couples diagnosed with infertility, aged 18 to 49 years were enrolled in the study. Details like couple's sociodemographic data, etiology, risk factors associated with infertility, management with current medications, procedures, and outcomes were documented using predesigned infertility proforma.

Results: Females had an age group of 19 to 38 years with an average age and standard deviation (SD) of $25.64 \pm 4.07$ years, whereas male patients had an age of 24 to 43 years with a mean age and SD of $30.59 \pm 4.17$ years. Primary infertility was $59.13 \%$ and secondary infertility $40.86 \%$. In women with infertility, ovulatory disorders were the chief cause, followed by unexplained factor, uterine tubal, and more than one cause, whereas in males semen abnormalities were the major cause of both primary and secondary infertility, followed by unexplained, anatomical, more than one cause. Medical therapy involving drugs like clomiphene, gonadotropins, and a combination was administered to females. Males received lycopene, L-carnitine, ubidecarenone, zinc, and astaxanthin. Intrauterine insemination (IUI) was performed in 28 patients. From the available data of 100 couples undergoing management for infertility in the 6 months study period, 19 patients conceived, i.e., $19 \%$ showed conception.

Conclusion: The present study shows etiological and pathological causes of infertility. The study highlights positive results with standard treatments.

Clinical significance: To identify hidden social, medical, pathological, and other confounding causes leading to infertility.

Keywords: Clomiphene, Gonadotropins, Intrauterine insemination, Observational study, Ovulation induction, Primary infertility, Secondary infertility.

\footnotetext{
${ }^{1,2}$ Student, ${ }^{3}$ Assistant Professor, ${ }^{4}$ Professor

${ }^{1-3}$ Department of Clinical Pharmacy, Bharati Vidyapeeth Deemed University, Pune, Maharashtra, India

${ }^{4}$ Department of Obstetrics and Gynecology, Bharati Hospital \& Research Centre, Bharati Vidyapeeth University Medical College \& Hospital, Pune, Maharashtra, India

Corresponding Author: Purvi K Khanuja, Student, Department of Clinical Pharmacy, Bharati Vidyapeeth Deemed University Pune, Maharashtra, India, Phone: +912024368227, e-mail: purvi1993@gmail.com
}

How to cite this article: Khanuja PK, Sunny JA, Pawar SB, Nimbargi V. Study on Infertility_Etiology, Medication Therapy Management, and Outcomes at a Tertiary Care Hospital. Int J Infertil Fetal Med 2017;8(3):106-112.

Source of support: Nil

Conflict of interest: None

Date of received: 09/07/2017

Date of acceptance: 12/08/2017

Date of publication: November 2017

\section{INTRODUCTION}

A dandelion is a universal symbol of fertility - the dozens of seeds released by each flower head represents fertility and abundance. The seeds journey illustrates a time of letting go, of starting something new [World Health Organization (WHO) 2009]. ${ }^{1}$

We are verbose when expressing bereavement of a parent, child, companion but no language can describe the agony of an absence. For those who want children and are deprived of it, those missing babies linger like tacit transitory voids over their lives. None can describe the touch of a tiny hand, i.e., never held.

Parenthood is irrefutably the most common desired objective and a fundamental event in adulthood where most people have life plans that include offspring. Human subsistence reaches comprehensiveness through a child, therefore, fulfilling the individual's requirement for reproduction associated with the ultimate goals of wholeness, contentment, and family amalgamation. Conversely, not all couples who desire gravidity will achieve one, and a fraction will need medical aid to resolve underlying fertility glitches. ${ }^{2}$ Infertility affects the reasonably large number of couples, i.e., approximately 8 to $10 \%$ couples worldwide. The WHO estimates that 60 to 80 million couples worldwide currently suffer from infertility. One in every four couples in developing countries has been found to be infertile. ${ }^{3}$ Infertility affects one in seven (14\%) couples in the UK, and in the US about $10 \%$ of women aged 15 to 44 , i.e., about 6.1 million women have difficulty getting pregnant or carrying a baby to term. ${ }^{4,5}$ It is a complex multidimensional malady with considerable medical, psychosocial, societal, cultural, and economic problems.

Sterile females are considered a bane to the culture and family. The unawareness about infertility is such that it is 
not unusual to find a male practicing polygamy, in order to continue his progeny. ${ }^{6}$

As the use of infertility medications is on a rise, the pharmacist's role too needs to be considered. The pharmacists can serve as an outstanding source to assist patients with their infertility medication education and counseling and management of any adverse drug reactions in a compassionate atmosphere. They too must be educated about the treatment options, causes, and risk factors that can lead to infertility. ${ }^{7}$

In India where traditionally having children is obligatory in terms of family contentment and many people still think of infertility as a "woman's problem," this problem acquires crucial social practicality. ${ }^{4}$ The present study is an endeavor to expand knowledge and increase the understanding of factors associated with male infertility, risk factors, and social habits causing infertility. To understand the magnitude, there is a need to search for various factors causing male and female infertility. The study also includes various cause-specific treatments given to both male and female partners and outcomes of the treatment in terms of conception.

\section{MATERIALS AND METHODS}

A prospective observational study was conducted between September 2015 and February 2016 at infertility outpatient department (OPD) of Bharati Hospital and Research Centre, Pune, India, to identify the etiologies and risk factors associated with infertility, to study the medical therapy, and assess outcomes of the treatment. During this 6-month period, 22,756 patients attended the gynecology OPD; from these 22,756 patients, 240 couples attended the fertility OPD. Out of those 240 couples, 100 consenting couples fulfilling the inclusion criteria were enrolled in the study. Couples diagnosed with either primary or secondary infertility, aged 18 to 49 years were registered. Unmarried, those aged above 49 years, patients recommended in vitro fertilization (IVF), and those diagnosed with infertility not willing to avail the treatment were excluded from the study. Ethical approval was obtained for the study from the Institutional Ethics Committee of Bharati Medical College and Research Centre, Pune (Institutional Ethics Committee Reg. No: ECR 518, REF: BVDU/MC/98). Patients' informed consent was taken for the study. The details like couple's sociodemographic data, which included age, gender, annual income, height, weight, body mass index (BMI), educational status, occupation, diagnosis, etiology, past medical, and medication history, along with current medications for management, procedures IUI, and outcomes were documented using a self-predesigned pro forma at the time of each follow-up.
The data gathered were tabulated in Microsoft Excel 2010 and IBM Statistical Package for the Social Sciences version 20 statistical software analyzed by appropriate statistical methods, where SD was calculated for age and $\mathrm{p}$ value, McNemar Chi-square test and t-test were applied for comparisons and percentage to evaluate conception rates.

\section{Study Criteria}

\section{Inclusion}

- Couples diagnosed with infertility and referred to the infertility clinic (outpatient basis)

- Couples aged 18 to 49 years

- Couples diagnosed with primary or secondary infertility.

\section{Exclusion}

- Unmarried/single

- Couples recommended and undergoing IVF as setup was not accessible during the study period at the hospital

- Couples diagnosed with infertility but not willing to avail the treatment

- Couples aged above 49 years

\section{RESULTS}

In the study duration of 6 months, 100 patients were enrolled, diagnosed with either primary or secondary infertility. The parameters, such as sociodemographic age, BMI, social habits, education, and occupation were calculated using percentages (Table 1), SD, and arithmetic mean evaluation (Table 2). A t-test was used to compare age in males and females with primary and secondary infertility. Mean, SD, and t values were evaluated with no significant difference in age-wise infertility rate (Table 3 ).

The social habits compared in case of males were alcoholism, tobacco, smoking, and occupational hazards if any and there was no significant effect on fertility rates in our study $\left(\mathrm{t}=-0.65, \mathrm{t}^{*}=1.94, \mathrm{p}=0.26\right)$.

Graph 1 compares the percentage of primary and secondary infertility, with primary infertility being greater than secondary infertility. We found the presence of both primary and secondary infertility being higher in females than males where the involvement of both was superior to males, indicating the contribution of both males and females to infertility. Out of the available data of 74 couples, 34 cases have both partners affected simultaneously. Out of the remaining 40 cases, 34 were female-related infertility, hence individual female infertility factor was found to be higher than male counterpart [ $\mathrm{McNemar}$ chi-square = 18.2, $\mathrm{p}<0.001$, highly significant (HS); Table 4]. 


\begin{tabular}{|c|c|c|c|c|c|c|c|c|}
\hline \multicolumn{3}{|c|}{ Table 1: Sociodemographic data } & \multicolumn{6}{|c|}{ Table 2: Age wise distribution of study subjects } \\
\hline \multirow[b]{2}{*}{ Patient characteristics } & \multirow{2}{*}{$\begin{array}{l}\text { Number of } \\
\text { patients }\end{array}$} & \multirow[b]{2}{*}{ Percentage } & \multicolumn{3}{|c|}{ Age and number of patients } & \multicolumn{3}{|c|}{ Value obtained } \\
\hline & & & \multicolumn{6}{|c|}{ Female (100) } \\
\hline Couples & 100 & & \multicolumn{3}{|c|}{ Average age } & \multicolumn{3}{|c|}{25.64} \\
\hline Gender & & & \multicolumn{3}{|c|}{ Standard deviation } & \multicolumn{3}{|c|}{04.03} \\
\hline Female & 100 & 100.00 & \multicolumn{6}{|c|}{ Male (69) } \\
\hline Male & 73 & 73.00 & \multicolumn{3}{|c|}{ Average age } & \multicolumn{3}{|c|}{30.57} \\
\hline Age (in years) & & & \multicolumn{3}{|c|}{ Standard deviation } & \multicolumn{3}{|c|}{04.17} \\
\hline Female & 100 & & From the & age of the couple & es avail & able, the me & ean aver & ge and \\
\hline $19-23$ & 33 & 33.00 & standarc & deviation of both & male a & id female $\mathrm{w}$ & vere calc & ulated \\
\hline 24-28 & 42 & 42.00 & & & & & & \\
\hline 29-33 & 21 & 21.00 & & & & & & \\
\hline $34-38$ & 04 & 04.00 & Table & $\begin{array}{r}\text { 3: Comparison of } \\
\text { and se }\end{array}$ & $\begin{array}{l}\text { f male } \\
\text { econdar }\end{array}$ & $\begin{array}{l}\text { and female } \\
\text { infertility }\end{array}$ & ages in $\mathrm{p}$ & rimary \\
\hline Male & 69 & & & & & & & \\
\hline $24-28$ & 25 & 36.23 & & Group s & statistic & & & \\
\hline $29-33$ & 26 & 37.68 & Group & $n$ & Mean & $\begin{array}{l}\text { Standard } \\
\text { deviation }\end{array}$ & t-value & $p$-value \\
\hline $34-38$ & 14 & 20.29 & $\begin{array}{l}\text { Group } \\
\text { Female }\end{array}$ & $\begin{array}{ll} & 11 \\
\text { Primary } & 27\end{array}$ & 25.89 & 3.724 & 0.253 & $0.801 \mathrm{NS}$ \\
\hline $39-43$ & 04 & 05.81 & $\begin{array}{l}\text { Female } \\
\text { age }\end{array}$ & $\begin{array}{l}\text { Primary } \\
\text { infertility }\end{array}$ & & $3 . / 24$ & & $0.801 \mathrm{NS}$ \\
\hline Body mass index & & & & Secondary 73 & 25.66 & 4.184 & & \\
\hline Female & 88 & & & infertility & & & & \\
\hline Normal & 45 & 51.13 & Male & Primary 17 & 29.29 & 3.424 & 1.449 & $0.152 \mathrm{NS}$ \\
\hline Underweight & 06 & 06.82 & age & infertility & & & & \\
\hline Overweight & 37 & 42.05 & & Secondary 52 & 30.98 & 4.372 & & \\
\hline Social habits & & & & infertility & & & & \\
\hline Male & 49 & & $\mathrm{H}_{0}: \mathrm{No}$ & ignificant differen & cee in a & ge in prime & ary and & econdary \\
\hline Alcohol & 09 & 18.75 & infertility; & $\mathrm{H}_{1}$ : Significant diffe & erence & age in prin & nary and & secondary \\
\hline Smoking & 01 & 02.08 & & & & & & \\
\hline Tobacco & 10 & 20.83 & & & & & & \\
\hline Tobacco + alcohol & 03 & 06.25 & & & & & & \\
\hline Smoking + alcohol & 01 & 02.08 & 80 & & & & & \\
\hline Tobacco + alcohol + smoking & 00 & 00.00 & & & & & & \\
\hline No addiction & 25 & 52.08 & & $59.14 \%$ & & & & \\
\hline Education & & & & & & & & \\
\hline Female & 33 & & & & & & & \\
\hline Primary (up to 10 th) & 13 & 39.39 & & & & & $40.86 \%$ & \\
\hline Secondary (up to 12th) & 05 & 15.15 & & & & & & \\
\hline Graduate & 12 & 36.36 & $\stackrel{0}{0}$ & & & & & \\
\hline Postgraduate & 03 & 09.09 & & & & & & \\
\hline Illiterate & 00 & 00.00 & 20 & & & & & \\
\hline Male & 30 & & & & & & & \\
\hline Primary (up to 10th) & 10 & 33.33 & & & & & & \\
\hline Secondary (up to 12th) & 07 & 23.33 & & Primary & & & econdary & \\
\hline Graduate & 07 & 23.33 & & & & & & \\
\hline Postgraduate & 04 & 13.66 & & Graph 1 & 1: Types & of infertility & & \\
\hline $\mathrm{CA}$ & 01 & 03.33 & & & & & & \\
\hline Illiterate & 01 & 03.33 & In $\mathrm{w}$ & omen with prim & tary in & ertility, ov & ulatory & disorders \\
\hline Occupation & & & {$[32(58$.} & $8 \%)$ ] were the & comn & lonest cat & use, foll & owed by \\
\hline Female & 69 & & uterine & actors in 2 (3.64 & $4 \%$ ) an & tubal fac & ctors in & $(3.64 \%)$ \\
\hline Housewife & 40 & 57.97 & while o & her factors acc & counte & d for 3 & $5.45 \%)$ & nd more \\
\hline Job & 21 & 30.43 & than on & cause in 4 & $27 \%)$ & nd unexp & lained & nfertility \\
\hline $\begin{array}{l}\text { Student } \\
\text { Business }\end{array}$ & 02 & $\begin{array}{l}02.89 \\
08.69\end{array}$ & $\begin{array}{l}\text { than on } \\
\text { in } 5(9.0\end{array}$ & $9 \%)$ & & 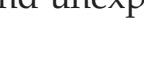 & (2) & and \\
\hline $\begin{array}{l}\text { Business } \\
\text { Male }\end{array}$ & $\begin{array}{l}06 \\
67\end{array}$ & 08.69 & In $\mathrm{m}$ & ales with prim & lary in & ertility, se & emen ab & normali- \\
\hline Job & 44 & 65.67 & ties wer & e the commone & est cav & se $[15(27$ & $7.27 \%)]$ & followed \\
\hline Engineer & 05 & 07.46 & by anat & omical conditio & ons [4 & $(7.27 \%)] \mathrm{a}$ & and othe & er factors \\
\hline Business & 17 & 25.37 & {$\left[3\left(5.45^{\circ}\right.\right.$} & o)], each follow & ved by & more tha & an one & condition \\
\hline $\mathrm{CA}$ & 01 & 01.49 & [3 $\left(5.45^{\circ}\right.$ & o)] and unexpla & ained $\mathrm{i}$ & afertility $\mathrm{i}$ & in $4(7.2$ & $7 \%)$ \\
\hline
\end{tabular}


Study on Infertility—Etiology, Medication Therapy Management, and Outcomes

Table 4: Comparison of male and female infertility

\begin{tabular}{|c|c|c|c|c|}
\hline & & \multicolumn{2}{|c|}{ Female } & \multirow[b]{2}{*}{ Tota } \\
\hline & & $N$ & $Y$ & \\
\hline \multirow[t]{2}{*}{ Male } & $\mathrm{N}$ & 0 & 34 & 34 \\
\hline & $Y$ & 6 & 34 & 40 \\
\hline Total & & 6 & 68 & 74 \\
\hline
\end{tabular}

$\mathrm{H}_{0}$ : Contribution of male gender in infertility; $\mathrm{H}_{1}$ : Significant contribution of female gender in infertility; Result: McNemar chi-square $=18.2, p<0.001 \mathrm{HS} ; \mathrm{H}_{0}$ is rejected and $\mathrm{H}_{1}$ is accepted
Table 5: Female factors: Etiology

\begin{tabular}{lll}
\hline & Female factors & \\
\hline Female factor & Number & Percentage \\
\hline Available & 87 & \\
Tubal factors & 4 & 4.59 \\
Uterine factors & 6 & 6.89 \\
Ovulatory disorders & 50 & 57.47 \\
(1) WHO Class I & 0 & 0 \\
(2) WHO Class II & 48 & 96 \\
(3) WHO Class III & 2 & 4 \\
More than one cause & 10 & 11.49 \\
Unexplained & 9 & 10.34 \\
Others & 8 & 9.19 \\
\hline
\end{tabular}

Table 6: Comparison between ovulatory disorders vs nonovulatory disorders

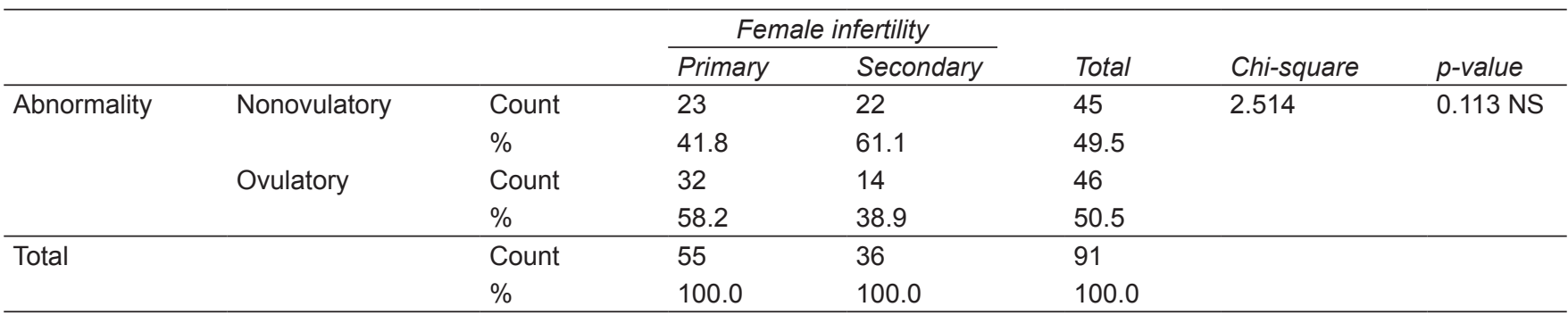

$\mathrm{H}_{0}$ : Nonovulatory disorders contribute majorly in causing primary and infertility; $\mathrm{H}_{1}$ : Ovulatory disorders contribute majorly to cause primary and secondary infertility; Result: $\mathrm{H}_{0}$ is accepted and $\mathrm{H}_{1}$ is accepted

In women with secondary infertility, ovulatory disorder was present in 14 (36.84\%), followed by uterine factors in $4(10.52 \%)$, tubal factors in $2(5.36 \%)$, and other factors in $5(13.15 \%)$, more than one cause in $5(13.15 \%)$ and unexplained causes in $6(15.78 \%)$. In males with secondary infertility, semen abnormalities accounted for 4 (10.53\%), followed by anatomical abnormality [2 (5.26\%)], others [2 (5.26\%)], and unexplained causes [4 (10.53\%)].

Table 5 depicts risk factors and etiology leading to female infertility along with the ovulatory disorder classification.

Table 6 shows a comparison of ovulatory disorders vs nonovulatory disorders in both primary and secondary infertility [chi-square $=2.514$, p-value $=0.113$,

Table 7: Male factors: Etiology

\begin{tabular}{lll}
\hline Male factor & Number & Percentage \\
\hline Available & 73 & \\
Nothing significant & 38 & 52.05 \\
Semen abnormality & 21 & 28.73 \\
(1) Asthenospermia & & 9.52 \\
(2) Oligozoospermia & & 23.81 \\
(3) Azoospermia & & 28.57 \\
(4) Teratozoospermia & & 4.76 \\
(5) Oligoasthenospermia & & 23.81 \\
(6) Oligoazoospermia & & 9.52 \\
Mild varicocele & 01 & 01.37 \\
Erectile dysfunction & 02 & 02.73 \\
Lack of coital activity & 05 & 06.85 \\
Infections & 02 & 02.73 \\
More than one condition & 04 & 05.48 \\
\hline
\end{tabular}

nonsignificant (NS)], where ovarian anomalies predominated though were statistically insignificant.

Table 7 portrays the risk factors and etiology leading to male infertility, and Table 8 depicts a comparison of seminal ws nonseminal factors in both primary and secondary infertility (chi-square $=1.42, \mathrm{p}=0.233 \mathrm{NS}$ ), where seminal abnormalities predominated though were statistically insignificant.

Table 9 indicates medical therapy involving standard drugs that are calculated in percentage. Males received lycopene, L-carnitine, ubidecarenone, zinc, and astaxanthin combination, whereas females were treated with clomiphene, gonadotropins, and combination therapy. Tubal etiologies of infertility were managed by laparoscopic tubal surgery.

Graph 2 indicates IUI performed in different etiologies. Intrauterine insemination was performed in 28 patients.

Table 10 describes different drug therapies administered to the patients. Strategies included clomiphene alone, gonadotropins alone, and combination of clomiphene and gonadotropins. We found no significant superior efficacy of one treatment strategy over the other.

From the available follow-up data of 100 couples undergoing management for infertility in the 6-month study period, 19 patients conceived, i.e., 19\% showed positive outcome. Method of conception among the 19 patients was divided into IUI, medication, and surgery and counseling, and the percentage is calculated from the available data (Graph 3). 
Table 8: Comparison between seminal vs nonseminal causes

\begin{tabular}{|c|c|c|c|c|c|c|c|}
\hline & & & \multicolumn{2}{|c|}{ Male infertility } & \multirow[b]{2}{*}{ Total } & \multirow[b]{2}{*}{ Chi-square } & \multirow[b]{2}{*}{$p$-value } \\
\hline & & & Primary & Secondary & & & \\
\hline \multirow[t]{4}{*}{ Abnormality } & Nonseminal abnormality & Count & 30 & 20 & 50 & 1.424 & $0.233 \mathrm{NS}$ \\
\hline & & $\%$ & 66.7 & 83.3 & 72.5 & & \\
\hline & Seminal abnormality & Count & 15 & 4 & 19 & & \\
\hline & & $\%$ & 33.3 & 16.7 & 27.5 & & \\
\hline \multirow[t]{2}{*}{ Total } & & Count & 45 & 24 & 69 & & \\
\hline & & $\%$ & 100.0 & 100.0 & 100.0 & & \\
\hline
\end{tabular}

$\mathrm{H}_{0}$ : Nonseminal factors contribute majorly in causing primary and infertility; $\mathrm{H}_{1}$ : Seminal factors contribute majorly to cause primary and secondary infertility; Result: $\mathrm{H}_{0}$ is accepted and $\mathrm{H}_{1}$ is accepted

Table 9: Medical therapy

\begin{tabular}{llll}
\hline \multicolumn{3}{c}{ Medical therapy } \\
\hline Etiology & Clomiphene (\%) & Gonadotropins & $\begin{array}{l}\text { Clomiphene }+ \\
\text { gonadotropins }\end{array}$ \\
\hline $\begin{array}{l}\text { Unexplained } \\
\text { Ovulatory }\end{array}$ & 22.58 & 19.35 & 16.13 \\
$\begin{array}{l}\text { disorders } \\
\text { Uterine } \\
\text { factors }\end{array}$ & 0 & 15.00 & 13.00 \\
\hline
\end{tabular}

\section{DISCUSSION}

The study was carried out at the Fertility Clinic of OBGYN at Bharati Hospital and Research Centre. In our study, 22,756 couples visited the gynecology OPD of Bharati Hospital in 6 months, i.e., from September 2015 to February 2016; from these 22,756 patients, 240 couples visited the infertility OPD. Out of those 240 couples, 100 couples were included in the study. The age of female patients was 19 to 38 years with a mean and SD of $25.64 \pm 4.03$ years. The males had an age of 24 to 43 years with a mean and SD of $30.57 \pm 4.17$ years. Higher $\%$ of females $(42 \%)$, i.e., 42 , was in the age group 24 to 28 years and $26(37.68 \%)$ males were in the age group of 29 to 33 years. This result is similar to a study conducted by Upadhyay et al, which established that age of female patients was 22 to 40 years with a mean and SD of $28.14 \pm 3.78$ years. The males had an age of 23 to

Table 10: Drug therapy comparison

\begin{tabular}{|c|c|c|c|c|c|}
\hline & & & \multicolumn{2}{|c|}{ Outcome } & \multirow[b]{2}{*}{ Total } \\
\hline & & & $N$ & $Y$ & \\
\hline \multirow{8}{*}{$\begin{array}{l}\text { Drug } \\
\text { therapy }\end{array}$} & \multirow[t]{2}{*}{ Clomiphene } & Count & 11 & 3 & 14 \\
\hline & & $\%$ received & 78.6 & 21.4 & 100.0 \\
\hline & \multirow[t]{2}{*}{ Gonadotropins } & Count & 7 & 0 & 7 \\
\hline & & $\%$ received & 100.0 & 0 & 100.0 \\
\hline & \multirow{2}{*}{$\begin{array}{l}\text { Clomiphene + } \\
\text { gonadotropin }\end{array}$} & Count & 13 & 2 & 15 \\
\hline & & $\%$ received & 86.7 & 13.3 & 100.0 \\
\hline & \multirow[t]{2}{*}{ Other } & Count & 16 & 4 & 20 \\
\hline & & $\%$ received & 80.0 & 20.0 & 100.0 \\
\hline \multirow[t]{2}{*}{ Total } & & Count & 47 & 9 & 56 \\
\hline & & $\%$ received & 83.9 & 16.1 & 100.0 \\
\hline
\end{tabular}

$\mathrm{H}_{0}$ : Single treatment effectiveness $\mathrm{H}_{1}$ : Combination therapy effectiveness; Result: $\mathrm{H}_{0}$ is accepted and $\mathrm{H}_{1}$ is accepted

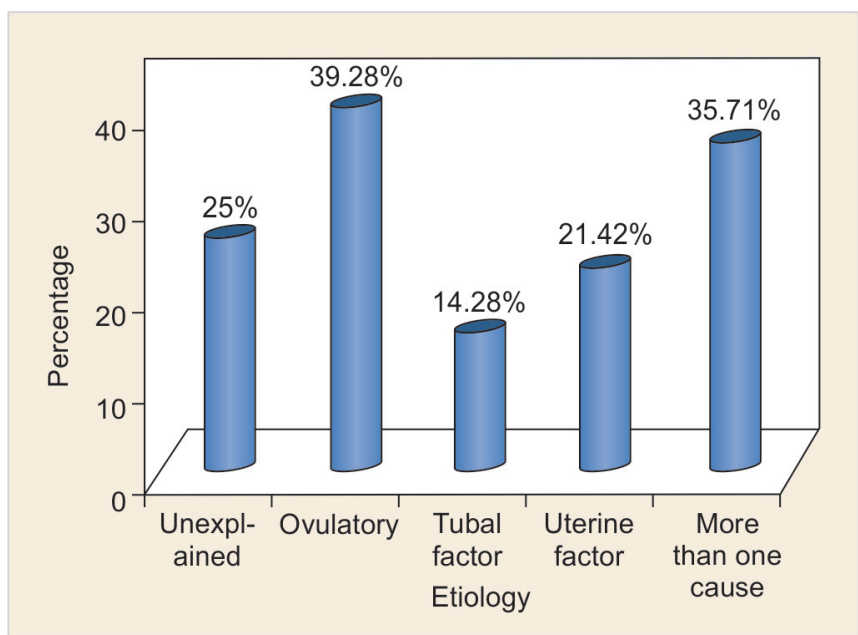

Graph 2: Intrauterine insemination performed for different etiologies

46 years with a mean and SD of $32.74 \pm 4.47$ years. Higher $\%$ of females were from the age group 25 to 29 years $(55.2 \%)$ and $43 \%$ males were in the age group of 30 to 34 years. ${ }^{8}$ Similarly, in the study conducted by Mittal et al, mean age and $\mathrm{SD}$ of the wife was $33.19 \pm 5.46$ years in the age group 22 to 45 years, while husbands' mean age and SD was 37.5 \pm 5.82 in the age 24 to 52 years, which is slightly different to our study results. ${ }^{4}$ Results were also comparable to study conducted by Farhi et al. ${ }^{9}$ The study couples had a marital history of 5 months to 12 years.

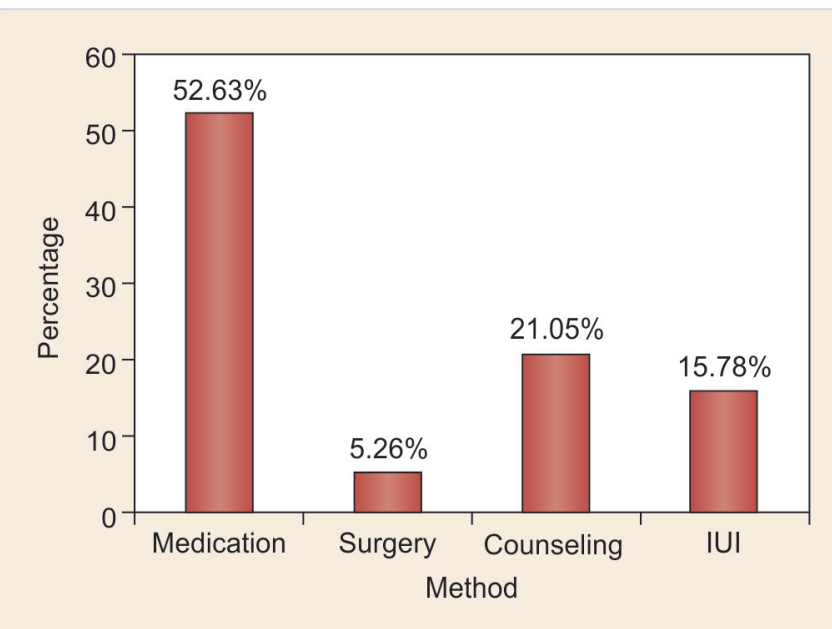

Graph 3: Methods of conception 
Incidence of primary infertility was $59.14 \%$ and that of secondary infertility was $40.86 \%$, whereas primary infertility was $48.30 \%$ and secondary infertility was $27.60 \%$ in the study conducted by Upadhyay et $\mathrm{al}^{8}$ and when compared with the results by Shamila and Sasikala ${ }^{10}$ confirmed the incidence of primary infertility to be $82.48 \%$ and secondary infertility to be $17.52 \%$.

Out of 100 male's data on social habits, data of 48 were available in which 9 (18.75\%) were alcoholic, 1 (2.08\%) was a smoker, 10 (20.83\%) consumed tobacco, 3 (6.25\%) consumed tobacco plus alcohol, and 1 (2.08\%) smoked and consumed alcohol. The present study shows no statistical significance. The study conducted by Samal et $\mathrm{al}^{11}$ confirmed the relationship between consumption of alcohol and smoking with infertility. It was found that addictions like smoking, alcohol, and tobacco chewing, and combinations of these had a detrimental effect on spermatogenesis. Excessive alcohol consumption has been linked to poor reproductive function. Infertility escalates as a result of smoking.

From 100 female's data on BMI, data of 88 females were available where $45(51.13 \%)$ had normal weight, $6(6.82 \%)$ were underweight, and 37 (42.05\%) females were overweight. Ovarian dysfunction could be associated with either unwarranted weight loss or excessive weight gain with BMI above $27 \mathrm{~kg} / \mathrm{m}^{2}$, as explained by Olooto et al. ${ }^{12}$ Another study conducted by Manna et $\mathrm{al}^{13}$ confirmed $30.89 \%$ infertile women were overweight and $6.28 \%$ infertile women are underweight comparable to our study results. Obesity proved to be significantly associated with primary infertility in the study conducted by Saoji. ${ }^{14}$

Among couples with primary infertility, male factors were responsible in $2(3.63 \%)$, female factors in 31 (56.36\%), and both partners were accountable in 22 (40\%).

Out of the available data of 74 couples, 34 cases have both partners affected simultaneously. Out of remaining 40 cases, 34 were female-related infertility, hence individual female infertility factor was found to be higher than male counterpart (McNemar chi-square $=18.2$, $\mathrm{p}<0.001$ HS).

In women with primary infertility, ovulatory disorders [32 (58.18\%)] were the commonest cause followed by uterine factors in $2(3.64 \%)$ and tubal factors in $2(3.64 \%)$, other factors accounted for $3(5.45 \%)$ cases and more than one cause in $4(7.27 \%)$ and unexplained infertility in $5(9.09 \%)$.

In males with primary infertility, the commonest cause is semen abnormality [15 (27.27\%)] followed by anatomical conditions [4 (7.27\%)] and other factors [3 (5.45\%)], each followed by more than one condition [3 (5.45\%)] and unexplained infertility in 4 (7.27\%).

In women with secondary infertility, ovulatory disorder was present in 14 (36.84\%), followed by uterine factors in 4 (10.52\%), tubal factors in $2(5.36 \%)$, and other factors in 5 (13.15\%), more than one cause in 5 (13.15\%) and unexplained causes in $6(15.78 \%)$. In males with secondary infertility, semen abnormalities accounted for $4(10.53 \%)$, followed by anatomical abnormality [ 2 $(5.26 \%)]$ and others [2 (5.26\%)] and unexplained causes [4 (10.53\%)].

A study conducted by Shamila and Sasikala ${ }^{10}$ on risk factors affecting female infertility in South Indian districts of Tamil Nadu and Kerala reports a positive correlation between infertility and menstrual irregularity. Similarly, a study conducted by Upadhyay et $\mathrm{al}^{8}$ too confirmed ovulatory disorders as a significant cause of infertility, which is comparable to our study.

Whereas the study results of Mittal et al reported ovulatory disorder as the commonest cause, followed by tubal blockage in females with primary infertility, i.e., $43(15.75 \%)$ and $31(11.36 \%)$ respectively, it was observed that tubal blockage and pelvic inflammatory disease lead to secondary infertility in approximately $20 \%$ couples. $^{3}$

A study by Samal et al ${ }^{11}$ distributed cases according to semen analysis reports and type of infertility and showed in case of primary infertility, 1,005 (54.03\%), 617 (33.17\%), $184(9.89 \%), 34(1.83 \%)$, and 20 (1.08\%) were normozoospermic, oligospermic, azoospermia, asthenozoospermia, and teratoasthenozoospermic respectively. In cases of secondary infertility, 795 (76.15\%), 229 (21.93\%), 12 $(1.15 \%)$, and $8(0.77 \%)$ were normozoospermic, oligospermic, azoospermic, and asthenozoospermic respectively. Teratoasthenozoospermia was not found in secondary infertility during the study.

The IUI was performed in 28 patients.

- Couples with unexplained infertility: 7 out of 13 cases-25\%

- Couples with ovulatory disorder: 11 out of 50 cases-39.28\%

- Couples with tubal factor: 4 out of 4 cases-14.28\%

- Couples with uterine factors: 2 out of 6 cases-21.42\%

- Couples with other etiology: 4 out of 10 cases-35.71\% From the available follow-up data of 100 couples undergoing management for infertility in the 6-month study period, 19 patients conceived, i.e., 19\% showed positive outcome (conception). The method of conception among the 19 patients was divided into IUI, medication, and surgery and counseling and the percentage is calculated from available data.

- $4(21.05 \%)$ conceived by IUI

- $10(52.63 \%)$ by medications

- $1(5.26 \%)$ by surgery

- $4(21.05 \%)$ by counseling spontaneously.

Eleven female patients conceived by IUI after undergoing ovulation induction with clomiphene citrate, while 5 female patients conceived by ovulation induction only 
without IUI in the study conducted by Upadhyay et $\mathrm{al}^{8}$ similar to our study.

\section{Tubal Factors (4 cases)}

Surgery (laparoscopy/laparotomy/adenosynchiolysis) was performed in these cases to restore the tubal patency once tubal blockage was confirmed by hysterosalpingogram and ultrasonography, and fertility was restored.

\section{LIMITATIONS}

- The sample size being small may not be adequate to reflect the exact scenario.

- Couples undergoing IVF were not included as IVF setup was not accessible during the study period at the hospital.

- Further studies with a large sample size and for a longer duration to assess patients on a long-term basis must be carried out for accurate results.

- Consideration of pharmacoeconomic aspects as infertility treatment is exorbitant.

\section{CONCLUSION}

The risk factors associated with infertility in females were increased BMI (obesity) and those in males were addiction to smoking, alcohol, and tobacco. Our study found no statistical significance pertaining to the above-mentioned risk factors in males and females. Primary infertility was high as compared with secondary infertility. Among the etiologies, the ovulatory disorders were most common followed by unexplained, tubal, and uterine factors. Male factors account for almost half of the cases where sperm abnormalities were a common cause.

The medications used in the study were ovulation induction medications, i.e., clomiphene, gonadotropins, and combination of clomiphene and gonadotropins, whereas males were prescribed lycopene for semen abnormalities.

Conception rates in the study were $19 \%$. This included ovulation induction medications, IUI, and counseling. All aspects relating to the cause, risk factors, management, and outcomes are therefore, addressed in the study.

\section{ACKNOWLEDGMENTS}

Authors thank their parents for supporting them through the tough days of their lives. They would like to thank $\mathrm{Dr}$ Vandana Nimbargi, Professor, Department of Obstetrics and Gynecology, Bharati Hospital and Research Centre, Pune, Maharashtra, India, for her guidance. They also thank Mrs. Sunita Pawar, Assistant Professor, Department of Clinical Pharmacy, Poona College of Pharmacy for her warm encouragement. Authors give special thanks to sister nurse Anuradha of the Infertility clinic for her extensive help.

\section{REFERENCES}

1. Infertility treatments for women-a review of biomedical evidence full report. The Women's Health Council. Available from http:/ /health.gov.ie/wpcontent/uploads/2014/03/ infertBiomedEvid_Summary.pdf

2. Bovin J, Bunting L, Collins JA, Nygren KG. International estimates of infertility prevalence and treatment seeking: potential need and demand for infertility medical care. IJIMS 2007 Jun;22(6):1506-1512.

3. Mittal A, Yadav S, Yadav SS, Bhardwaj A, Kaur R, Singh P, et al. An epidemiological study of infertility among urban population of Ambala, Haryana. IJIMS 2015;2(4):124-130.

4. National Institute for Health and Care Excellence (NICE). Assessment and treatment for people with fertility problems [Online]; 2013. Available from: http://www.nice.org.uk/ guidance $/ \operatorname{cg} 156$

5. Chandra A, Copen CE, National Centre for Health Statistics; Stephen EH. Infertility and impaired fecundity in the United States, 1982-2010: data from the national survey of family growth. Natl Health Stat Report 2013 Aug;(67):1-20.

6. Manna N, Pandit D, Biswas S. Infertility and related factors: an experience from a rural community of West Bengal India. Indian J Prev Soc Med 2014;45(1-2):30-34.

7. Barnes M and Wiemer D. (2015). Available from https:// www.uspharmacist.com/ce/therapeutic-management-ofinfertility-a (Accessed 30 Sep. 2015).

8. Upadhyay N, Shakya R, Shrivastava U, Paudel P. A study on management of anovulatory infertility in urban Nepalese population. World J Pharm Sci 2015;3(5):840-845.

9. Farhi J, Ben-Haroush A. Distribution of causes of infertility in patients attending primary fertility clinics in Israel. IMAJ 2011 Jan;13(1):51-54.

10. Shamila S, Sasikala SL. Primary report on risk factors affecting female infertility in South Indian districts of Tamil Nadu and Kerala. Indian J Commun Med 2011 Jan-Mar;36(1):59-61.

11. Samal S, Dhadwe K, Gupta NK, Gupta U. Epidemiological study of male infertility. Indian Med Gazette 2012 May;146(5):174-180.

12. Olooto and Eniola W. Infertility in male; risk factors, causes and management-a review. J Microbiol Biotech Res 2012;2(4):641-645.

13. Manna N, Pandit D, Bhattacharya R, Biswas S. A community based study on infertility and associated socio-demographic factors in West Bengal, India. IOSR-JMDS 2014 Feb;13(2):13-17.

14. Shamila S, Sasikala S. Primary Report on the Risk Factors Affecting Female Infertility in South Indian Districts of Tamil Nadu and Kerala. Vol. 36, Indian journal of community medicine: official publication of Indian Association of Preventive \& Social Medicine. 2011. pp. 59-61. 